\title{
PERLINDUNGAN HUKUM TERHADAP WAITRESSDI CAFE KATULEBO BERDASARKAN UNDANG-UNDANG NOMOR 13 TAHUN 2003 TENTANG KETENAGAKERJAAN
}

\author{
Ida Bagus Alit Segara Gita, Nella Hasibuan Oleary, I Putu Gede Seputra \\ Fakultas Hukum, Universitas Warmadewa, Denpasar, Bali
}

\begin{abstract}
Abstrak
Waitress biasanya bekerja menuangkan minuman yang Dipesan tamu ke dalam gelas lalu mendampingi tamu bersenandung semasih duduk di Cafe. Berdasarkan hukum ketenagakerjaan perlindungan hukum yang didapatkan yaitu perlindungan hukum dibagian keamanan bekerja, dalam hal ini baik dari durasi yang relative cepat/lama hendak terjaga juga terdapat tanggungan keamanan terhadap pekerja. Dalam hal pertanggungjawaban kepada pekerjanya bila terjadi kecelakaan kerja saat melaksanakan kewajibannya dalam bekerja Maka pengusaha yang menanggung beban yang muncul secara materiil dengan memberikan penggantian dari biaya muncul akibat kecelakaan kerja sesuai uraian tersebut penulis mendapatkan judul Perlindungan Hukum Terhadap Waitress Di Cafe Katulebo Berdasarkan Undang-Undang Nomor 13 Tahun 2003 Tentang Ketenagakerjaan. Tujuan penelitian ini adalah untuk mengetahui perlindungan hukum yang diberikan oleh Cafe Katulebo kepada Waitress menurut Undang-Undang No 13 Tahun 2003 Tentang Ketenagakerjaan dan untuk mengetahui pertanggungjawaban Cafe Katulebo terhadap Waitress pada kecelakaan kerja. Dalam prakteknya pelaksanaan perlindungan hukum yang diberikan pihak Cafe kepada Waitress hanya melalui sebuah perjanjian tertulis yang berisi peraturan dan hak apa saja yang diperoleh oleh Waitress. Adapun bentukpertanggungjawaban yang diberikan oleh pihak Cafe terhadap Waitress hanya memberi persediaan kotak P3K dan uang santunan bila terjadi kecelakaan kerja. Metode penulis an yang digunakan adalah penelitian hukum empiris.
\end{abstract}

Kata Kunci: Ketenagakerjaan; Perlindungan Hukum; Waitress Cafe

\begin{abstract}
Waitress is usually tasked with pouring the drink that visitors ordered into a glass and accompanying visitors to sing while in the Cafe. In labor law legal protection is provided in the form of legal protection in the field of job security where both in a relatively short or long time will be safe and there is a guarantee of safety for workers. In the case of liability to workers in the event of a work accident while carrying out theirobligations at work the employer will bear the burden Arising materially by providingreimbursement for costs incurred due to work accidents based on the description the author gets the title Legal Protection Against Waitress at Katulebo Cafe Based on the Law Law Number 13 of 2003 concerning Employment. The aims of this study are to find out the legal protection provided by Katulebo Cafe to Waitresses according to Law No. 13 of 2003 concerning Employment and to find out the responsibility of Katulebo Cafe for Waitresses in work accidents. In practice the implementation of legal protection provided by the Cafe to the Waitress is only through a written agreement containing the regulations and what rights are obtained by the Waitress. The form of responsibility given by the Cafe to the Waitress only provides a first-aid kit and compensation when work accidents occur. The writing method used is empirical legal research.
\end{abstract}

Keywords: Labors; Legal Protection; Waitress Cafe

\section{PENDAHULUAN}

Usaha untuk membuat kesempatan kerja agar menanggulangi angka pengangguran dan juga mengumpulkan tambahan jumlah Pekerja adalah penggalan pada semua prosedur dan rencana kerja pembaharuan. Juga semua peraturan dan program pengembangan sosial ekonomi mengevaluasi seluruhnya misi-misi pelebaran peluang kerja juga aktivitas usaha yang luas menampung pekerja (Trijono, 2014:14).

Perlindungan terhadap tenaga kerja diimplementasikan dengan dibuatnya UU No. 13 Tahun 2003 Tentang Ketenagakerjaan dalam Pasal 86 ayat (1) huruf a huruf b dan huruf c yang mengemukakan (1) Setiap tenaga kerja memiliki kewajiban dan hak agar mendapatkan pengamanan atas kedamaian dan 
kesejahteraan kerja akhlak dan susila juga tingkah laku yang sesuai dengan norma-norma hukum dan religi.

Secara hukum derajat pekerja ialah merdeka namun menurut ekonomi sosial pangkat pekerja yaitu tidak leluasa. Pada dasarnya derajat pekerja menurut hukum sesuai aturan Pasal 27 UUD 1945 merupakan serupa dengan atasannya. Namun dalam nyatanya dalam ekonomi sosial derajat antara buruh dengan atasan merupakan berbeda. Sebagai orang yang tidak memiliki modal hidup yang berlainan atas itu dia tertekan bertugas terhadap atasannya (Zainal Asikin 2004:5). Indonesia dengan serius menangani hal ini dengan membuat UU No.13 tahun 2003. Undang-undang ini dikeluarkan guna menjelaskan hak dan kewajiban masing-masing, (Ismail \& Zainuddin, 2019). Perlindungan hukum bagi buruh dalam sistem hukum ketenagakerjaan nasional meliputi: 1). Perlindungan tentang upah, kesejahteraan, jaminan sosial tenaga kerja; 2). Perlindungan keselamatan dan kesehatan kerja; 3). Perlindungan hukum untuk membentuk dan menjadi anggota serikat Pekerja/ serikat buruh; 4). Perlindungan atas hak-hak dasar pekerja / buruh untuk berunding; dengan pengusaha, (Suhartoyo, 2019). Menilik derajat buruh atau pekerja yang kian kecil ketimbang atasannya lalu butuh tersedianya turun tangan dari pemegang kekuasaan guna menyerahkan pengamanan hukumnya.

Beberapa penelitian terkait dengan penelitian sekarang ini telah dikaji sebelum, diantaranya: Sugita, Markeling, \& Sudarsana (2014); (Dewi, 2015); (Clinton, Lestari, \& Fitriani, 2016); (Kembaryana, Dunia, \& Sukranatha, 2016) dan (Suwantari \& Astariyani, 2019). Fakhrurraji (2018) mengkaji tentang "Implementasi Perundang-Undangan Ketenagakerjaan Terhadap Buruh Pasar Ditinjau Dari Perspektif Keadilan". Hasil penelitian ini menunjukkan bahwa implementasi perundangundangan Ketenagakerjaan terhadap buruh pasar tradisional di kota Takengon belum terlaksana dengan maksimal, sosialisasi maupun pendampingan terhadap pekerja belum dirasakan, sehingga prinsipprinsip keadilan bagi buruh pasar tradisional belum dapat dirasakan Hal ini disebabkan belum termuatnya secara tegas peraturan-peraturan yang melindungi para buruh pasar tradisional dari ancaman kesewenang-wenangan pemberi kerja. Selanjutnya, Tampubolon (2019) juga mengkaji penelitian serupa tentang "Perlindungan Hukum Terhadap Pekerja Penyandang Disabilitas Dalam Mendapatkan Pekerjaan Yang Layak (Studi Kasus di PT.Deaf Cafefingertalk Tangerang)". Berdasarkan analisis, hasil penelitian ini menunjukkan bahwa PT. Deaf Cafe Fingertalk Tangerang selaku perusahaan swasta yang mempekerjakan penyandang disabilitas sudah melaksanakan kewajibannya dengan memberikan pemenuhan hak - hak pekerja sebagaimana diatur dalam Undang - undang Nomor 13 Tahun 2003 Tentang Ketenagakerjaan. Berdasarkan latar belakang dan penelitian terdahulu di atas, tujuan penelitian ini adalah untuk mengetahui perlindungan hukum yang diberikan oleh Cafe Katulebo kepada Waitress menurut Undang-Undang No 13 Tahun 2003 Tentang Ketenagakerjaan dan untuk mengetahui pertanggungjawaban Cafe Katulebo terhadap Waitress pada kecelakaan kerja.

\section{METODE PENELITIAN}

Penelitian ini menggunakan tipe penelitian empiris, yaitu penelitian yang dicermati atas ciri hukum yang aktual selaras dengan fakta hidup di dalam lingkungan bermasyarakat. Oleh kerena itu observasi lapangan wajib dilaksanakan dilokasi dengan memakai kaidah teknik lapangan. Menurut sifatnya kajian yang dipakai adalah observasi yang sifatnya deskriptif. Dalam observasi ini menggunakan pendekatan sosiologi hukum dan pendekatan fakta. Pendekatan sosiologi hukum yaitu pendekatan berbentuk pembelajaran lapangan guna mendapatkan konsep tentang metode terjalin dan terhadap cara bertugasnya hukum. Dalam masyarakat yang berangkaian dengan observasi ini setelah itu terkait atas persoalan yang diulas. Pendekatan fakta yaitu pendekatan yang dibuat guna mendapatkan bukti yang timbul dilokasi yang terkait dengan persoalan dari sebab tersebut menyangkut perlindungan hukum untuk pekerja wanita yang bertugas di dalam Cafe. Adapun Data yang dipakai dalam observasi ini berasal dari data primer; data sekunder dan data tersier. Penelitian ini dilakukan di Cafe Katulebo Denpasar. Dari observasi ini metode pengumpulan bahan yang dipakai ialah bahan primer yang didapat dengan metode wawancara.

\section{HASIL DAN PEMBAHASAN}

\section{Perlindungan Hukum terhadap Waitress di Cafe Katulebo Berdasarkan Undang-Undang Nomor 13 Tahun 2003 tentang Ketenagakerjaan}

Dalam Pasal 1 angka 3 UU No. 13 tahun 2003 pekerja/buruh ialah semua orang yang bekerja dengan mendapatkan gaji atau imbalan dalam bentuk lain. Dari penjabaran diatas bahwa hanya pekerja yang 
telah bertugas yang dikatakan pekerja (Husni, 2001:12). Penjagaan tenaga kerja bisa dilaksanakan melalui suatu cara yakni dengan arahan ataupun melalui cara dengan menaikkan legalisasi HAM untuk melindungi baik fisik ataupun teknis dari pekerja tersebut agar terciptanya keamanan dan kesejahteraan bagi tenaga kerja yang akan bekerja di tempat mereka bekerja. Perlindungan hukum terhadap pekerja dapat dilakukan dengan perlindungan hukum reprentif dan perlingungan hukum represif, perlindungan hukum reprentif bertujuan untuk mencegah terjadinya sengketa, sedangkan perlindungan hukum represif bertujuan untuk menyelesaikan sengketa.

Dalam melaksanakan perlindungan terhadap tenaga kerja harus diusahakan adanya perlindungan dan perawatan yang layak bagi semua tenaga kerja dalam melakukan pekerjaannya sehari-hari terutama dalam bidang keselamatan kerja serta menyangkut norma-norma perlindungan tenaga kerja (Soedjono, 2000:42). Tujuan perlindungan tenaga kerja adalah untuk menjamin berlangsungnya sistem hubungan kerja secara harmonis tanpa disertai adanya tekanan dari pihak yang kuat kepada pihak yang lemah pengusaha wajib melaksanakan ketentuan perlindungan tenaga kerja sesuai peraturan perundangundangan yang berlaku (Khakim, 2007:103).

Berdasarkan observasi di lapangan pekerja wanita/Waitress di Cafe Katulebo tidak ada yang berusia di bawah 18 tahun dan wanita yang sedang hamil tidak dipekerjakan. Pihak manajemen Cafe berusaha mematuhi larangan pemerintah yang melarang pengusaha untuk mempekerjakan pada malam hari bagi perempuan/wanita yang berumur kurang dari 18 tahun atau wanita hamil. Cafe Katulebo buka mulai dari jam $12.00 \mathrm{~s} / \mathrm{d} 02.00$ wita dan mempekerjakan Waitress pada malam hari antara jam 17.00 sampai dengan 02.00 wita.

Berdasarkan wawancara dengan Pemilik Cafe Katulebo Ida Bagus Putra dan Waitressnya Diana Amrita pada tanggal 4 januari 2020 Pukul 16.30 Wita perjanjian kerja yang memuat kewajiban dan hak pengusaha Cafe Katulebo dan Waitress yakni:

1. Kewajiban Pengusaha kafe Katulebo dan Pekerja (Waitress)

a. Kewajiban Pengusaha kafe Katulebo

Membagikan upah atau imbalan, Membagikan tunjangan juga fasilitas dan memberikan keamanan dan keselamatan terhadap Waitress tersebut.

b. Kewajiban Waitress

Harus melaksanakan kerjaannya dan turut mentaati aturan dan arahan dari pemilik Cafe katulebo, harus mengganti rugi bila Waitress tersebut melakukan tindakan yang merugikan perusahaan Cafe, dalam hal ini dengan kesengajaan maupun kelalaian Waitress tersebut.

2. Hak Pengusaha Cafe Katulebo dan Waitress

a. Hak Pengusaha Cafe Katulebo

Menerima hasil dari kerja Waitress, bisa melakukan pemutusan hubungan kerja kepada Waitress bila Waitress tersebut sedikit atau tidak berkontribusi terhadap kerjaannya, memiliki hak untuk mendapat ganti kerugian bila Waitress melakukan kelalaian terhadap usaha Cafe tersebut yang menyebabkan kerugian.

b. Hak Waitress

Mendapatkan imbalan ataupun upah dari kerjaan yang dilaksanakan, Memperoleh tunjangan juga fasilitas, Memperoleh jaminan keamanan dan keselamatan diri selama hubungan kerja tersebut masih terjadi.

Menurut hasil wawancara pada tanggal 4 januari 2020 Pukul 16.30 Wita dengan Ida Bagus Putra sebagai pemilik Cafe Katulebo di Denpasar Pelaksanaan perlindungan hukum bagi Waitress yang bekerja pada malam hari di Cafe Katulebo yang diberikan belum sepenuhnya bisa menaati aturan PerUU yang berlaku yakni Undang-Undang Ketenagakerjaan dan hanya bisa memberikan perlindungan dan keamanan sesuai terhadap perjanjian kerja yang dibuat oleh Pemilik Cafe dan Waitress dimana Pihak Cafe memberikan perlindungan sesuai dengan hak-hak yang diperoleh oleh Waitress diantaranya:

1. Pemberian Upah sesuai Kinerja;

2. Pemberian makanan dan minuman yang cukup bervariasi;

3. Perlindungan kesusilaan dan keamanan selama di tempat kerja;

4. Pemisahan Kamar Mandi/WC yang layak dengan penerangan yang memadaii antara pekerja/buruh perempuan dan laki-laki;

Menurut data yang diperoleh dari Ida Bagus Putra pemilik Cafe Katulebo dalam wawancara pada tanggal 4 januari 2020 Pukul 17.00 WITA faktor penghambat pelaksanaan perlindungan hukum bagi Waitress di Cafe Katulebo tidak ada hambatan yang serius dimana setiap permasalahan dapat 
diselesaikan dengan cara musyawarah antara pihak pengusaha dengan Waitressnya. Tetapi kenyataannya dilokasi banyak Waitress yang belum mengerti terhadap perlindungan apa saja yang diberikan oleh pihak pengusaha kepada para Waitress. Dan juga tidak tersedianya kendaraan khusus untuk antar jemput bagi para pekerja khususnya Waitress yang bekerja di malam hari.

\section{Pertanggungjawaban Cafe Katulebo Terhadap Waitress bila Terjadi Kecelakaan Kerja}

Kecelakaan kerja kadangkala diperluas dengan meliputi penyakit akibat kerja. Ada 3 (tiga) jenis kecelakaan kerja yaitu

a. Golongan pertama yang mengartikan kecelakaan kerja secara sempit yaitu golongan yang hanya meliputi kecelakaan kerja yang terjadi di perusahaan saja.

b. Golongan kedua yang mengartikan kecelakaan yang bukan hanya terjadi di perusahaan saja tetapi juga penyakit yang timbul akibat hubungan kerja di perusahaan tempat bekerja.

c. Golongan ketiga yang mengartikan kecelakaan kerja secara luas yaitu jenis kecelakaan yang meliputi golongan pertama dan golongan kedua ditambah kecelakaan (lalu lintas) yang terjadi pada saat pulang dan pergi ke tempat kerja dengan melalui rute yang biasa dilalui (Asyhadie, 2008:131).

Berdasarkan Pendapat Manulang kecelakaan kerja, meliputi:

a. Kecelakaan kerja yang berlangsung di suatu tempat ataupun lingkungan bekerja, Kecelakaan kerja yang terjadi saat pekerja tersebut berangkat atau datang dari tempat ia bekerja selama perjalanan yang normal dan wajar dilalui sehari-hari Kecelakaan berlangsung di lokasi berbeda dengan agenda tugas ataupun yang berhubungan dalam pekerjaan juga bukan dalam hal berkepentingan individu, dalam hubungan kerja timbulnya penyakit yang memicu terjadinya kecelakaan kerja (Manulang, 200:115).

b. Berdasarkan observasi di Cafe Katulebo Kecelakaan kerja rawan terjadi karena keadaan tempat yang ramai akan pengunjung dan kurangnya pencahayaan atau remang-remang yang membuat resiko kecelakaan kerja dapat terjadi dan juga apabila tamu sudah tidak bisa mengontrol emosi karena pengaruh minuman beralkohol hal-hal yang memicu terjadinya kecelakaan terhadap Waitress pun besar pengaruhnya. Oleh sebab itu pemilik Cafe harus juga mengerti keadaan Cafenya yang ramai akan pengunjung dan juga kurangnya pencahayaan dimana membuat penglihatan menjadi rabun karena kurangnya pencahayaan tersebut.

Terdapat beberapa peraturan perundang-undangan di Indonesia yang mengatur mengenai kewajiban pengusaha untuk mendaftarkan pekerjanya pada program BPJS. Hal ini merupakan bentuk tanggung jawab dari Pemerintah dalam hal memberikan perlindungan bagi tenaga kerja di Indonesia namun pada kenyataannya tidak semua pengusaha menaati peraturan tersebut untuk memenuhi kewajibannya terutama kewajiban pengusaha Cafe untuk mendaftarkan Waitressnya karena Waitress yang bekerja pada malam hari lebih beresiko mengalami kecelakaan kerja.

Berdasarkan hasil wawancara dengan Ida Bagus Putra pemilik Café Katulebo pada tanggal 5 januari 2020 Pukul 16.00 Wita mengatakan bahwa pekerja wanita/Waitress yang bekerja di Cafe Katulebo tidak diikutsertakan atau tidak didaftarkan dalam program BPJS karena menganggap resiko kerja yang dimiliki Waitress tersebut sangat kecil sehingga tidak perlu untuk didaftarkan Hal ini menunjukkan masih adanya kesenjangan antara norma dengan kenyataan yang ada dilapangan.

Berdasarkan wawancara dengan Yanti Waitress Cafe Katulebo pada tanggal 5 Januari 2020 Pukul 16.30 Wita Yanti pernah mengalami kecelakaan kerja saat menemani tamu minum di Cafe Katulebo karena pengaruh alkohol tamu tersebut menyenggol botol minuman hingga pecah dan mengenai Yanti yang mengakibatkan luka dibagian kakinya. Bentuk pertanggung jawaban oleh Cafe Katulebo yakni:

1. Dana santunan berupa uang tiga ratus ribu rupiah (maksimal) kalau Waitress dirawat di Rumah Sakit dan rawat inap pihak Cafe mengganti sejumlah tiga ratus ribu rupiah (maksimal) dan tetap menghitung jam kerja Waitress yang izin berobat diluar semasih jam kerja.

2. Adanya kotak Pertolongan Pertama Pada Kecelakaan (selanjutnya disebut kotak P3K) untuk Waitress bila terjadi kecelakaan kerja dilingkungan kerja dirawat dan tidak perlu membayar. 
Bentuk pertanggungjawaban pemilik Cafe kepada Yanti yakni anggaran perawatan/pengobatan maksimal sejumlah tiga ratus ribu rupiah santunan tersebut diberikan apabila Yanti berobat diluar ataupun opnamejika ia berobat menggunakan kotak P3K di Cafe semua pengobatan dan obat diberikan secara gratis.

\section{SIMPULAN}

Berdasarkan uraian yang telah disebutkan di atas maka dapat disimpulkan bahwa 1) Perlindungan hukum yang diberikan oleh Cafe Katulebo kepada Waitress menurut Undang-Undang No 13 Tahun 2003 Tentang Ketenagakerjaan belum sepenuhnya dapat dilaksanakan perlindungan hukum yang diberikan pihak Cafe kepada Waitress hanya melalui sebuah perjanjian tertulis yang berisi peraturan dan hak apa saja yang diperoleh oleh Waitress yang bekerja di Cafe tersebut. 2) Pertanggungjawaban Cafe Katulebo terhadap Waitress bila terjadi kecelakaan kerja adalah dengan upaya perlindungan preventif dengan menyediakan kotak P3K yang dapat digunakan untuk berobat apabila terjadi kecelakaankerja dan upaya perlindungan represif yaitu memberikan santunan yaitu sebesar Rp. 300.000 (maksimum) untuk berobat diluar Cafe yang disediakan pihak Cafe serta tidak memotong jam kerja Waitress yang ijin berobat pada saat jam kerja. Adapun saran yang dapat diberikan yaitu: 1) diharapkan pengusaha Cafe dapat memenuhi kewajibannya untuk melaksanakan perlindungan terhadap pekerjanya sesuai dengan peraturan perundang-undangan dan tidak hanya sesuai perjanjian tertulis saja khususnya kewajiban untuk mendaftarkan pekerjanya pada program BPJS. 2) untuk mengecilkan beban semacam musibah para pekerja pemilik Cafe sebaiknya memaksimalkan upaya kesehatannya bagi keamanan tugas kepada pekerja. Seharusnya pemilik Cafe/donatur kerja mengasihkan diseminasi berarti keselamatan pekerja juga pemasyarakatan menyinggung tersedianya rencana tanggungan pengelolaan kemasyarakatan.

\section{DAFTAR PUSTAKA}

Asyhadie, Z. (2008). Hukum Kerja Hukum Ketenagakerjaan Bidang Hubungan Kerja. Jakarta: Rajawali Press.

Clinton, B., Lestari, R., \& Fitriani, R. (2016). Perlindungan Hukum Terhadap Hak Tenaga Kerja Wanita di PT. Beka Engineering Pangkalan Kerinci. Jurnal Online Mahasiswa: Fakultas Hukum, 3(2). Retrieved from https://jom.unri.ac.id/index.php/JOMFHUKUM/article/view/14912

Dewi, Y. I. P. P. (2015). Perlindungan Hukum Terhadap Pekerja Outsourcing Akibat Perbuatan Wanprestasi Prinsipal. Mimbar Keadilan, (November), 229-243. doi:10.30996/mk.v0i0.2122

Fakhrurraji, A. (2018). Implementasi Perundang-Undangan Ketenagakerjaan Terhadap Buruh Pasar Ditinjau Dari Perspektif Keadilan. RESAM Jurnal Hukum STIHMAT, 4(1), 31-44. doi:https://doi.org/10.32661/resam.v4i1.7

Husni, L. (2001). Pengantar Hukum Ketenagakerjaan Indonesia. Jakarta: PT. Raja Grafindo Persada.

Ismail, N., \& Zainuddin, M. (2019). Hukum dan Fenomena Ketenagakerjaan. Focus: Jurnal Pekerjaan Sosial, 1(3), 166-182. doi:10.24198/focus.v133.20494

Kembaryana, N. N., Dunia, N. K., \& Sukranatha, A. . K. (2016). Perlindungan Hukum Terhadap Tenaga Kerja Wanita: Studi Pada Alam Dini Resort Ubud Kabupaten Gianyar. Kertha Semaya: Journal Ilmu Hukum, 4(3). Retrieved from https://ojs.unud.ac.id/index.php/kerthasemaya/article/view/30021/

Khakim, A. (2007). Pengangar Hukum Ketenagakerjaan Indonesia. Bandung: PT. Citra Aditya Bakti. Manulang, S. H. (2001). Pokok-Pokok Hukum Ketenagakerjaan Indonesia. Jakarta: Bhineka Cipta. Soedjono, W. (2000). Hukum Perjanjian Kerja. Jakarta: Bina Aksara.

Sugita, N. S., Markeling, I. K., \& Sudarsana, I. K. S. (2014). Pelaksanaan Perlindungan Hukum Bagi Pekerja Wanita Yang Bekerja Pada Malam Hari di Hard Rock Cafe Kabupaten Badung. Kertha Semaya: Journal Ilmu Hukum, 2(2). Retrieved from https://ojs.unud.ac.id/index.php/kerthasemaya/article/view/8194/

Suhartoyo. (2019). Perlindungan Hukum Bagi Buruh Dalam Sistem Hukum Ketenagakerjaan Nasional. Adminitrative Law \& Governance Journal, 2(2), 326-336. doi:https://doi.org/10.14710/alj.v2i2.326\%20-\%20336

Suwantari, I. G. A. D., \& Astariyani, N. L. G. (2019). Perlindungan Hukum Terhadap Para Pekerja Yang Mengalami Pemutusan Hubungan Kerja Karena Dampak Digitalisasi. Kertha Semaya: Journal Ilmu Hukum, 6(7), 1-15. Retrieved from 
https://ojs.unud.ac.id/index.php/kerthasemaya/article/view/53864

Tampubolon, I. A. (2019). Perlindungan Hukum Terhadap Pekerja Penyandang Disabilitas Dalam Mendapatkan Pekerjaan Yang Layak (Studi Kasus di PT.Deaf Cafefingertalk Tangerang). Jurnal Pionir: Lembaga Penelitian Dan Pengabdian Masyarakat, 5(3). doi:https://doi.org/10.36294/pionir.v5i3.722

Trijono, R. (2014). Pengantar Hukum Ketenagakerjaan. Jakarta: Papas Sinar Sinanti. 